\title{
Criteria for Choosing Thermal Packaging for Temperature Sensitive Goods Transportation
}

\author{
Ilze VAMZA ${ }^{1 *}$, Karlis VALTERS ${ }^{2}$, Arnis DZALBS ${ }^{3}$, Edgars KUDURS $^{4}$, \\ Dagnija BLUMBERGA ${ }^{5}$ \\ ${ }^{1-5}$ Institute of Energy Systems and Environment, Riga Technical University, 12-k1 Azenes iela, Riga, \\ LV-1048, Latvia
}

\begin{abstract}
Today cold chain transportation has become more important than before, as countries rely on cold chain logistics to store and transport SARS-CoV-2 vaccines and other temperature-sensitive goods. The cold chain is usually associated with the use of non-renewable materials and higher energy consumption than the regular supply chain. An important part of cold chain sustainability is thermal packaging. Up to now one of the most popular thermal packaging materials is polystyrene - made from fossil raw material. Polystyrene has low thermal conductivity and density, but it breaks down into micro- and nano plastics when exposed to sunlight making it environmentally unsustainable. To determine which factors are important for cold chain regarding thermal packaging, 12 criteria were compared to determine their ranking. Further multi-criteria analysis was used to compare polystyrene to four alternative biodegradable thermal packaging options: mycelium-based, corn starch, non-woven wool, and non-woven feathers. Polystyrene gained only $3^{\text {rd }}$ place with a 0.70 proximity to ideal solution 1 , but non-woven wool showed the best result with 0.88 proximity to ideal solution.
\end{abstract}

Keywords - Cold chain; logistics; non-woven materials; sustainable packaging; polystyrene

\section{INTRODUCTION}

Temperature sensitive products have been challenging commodities as their transportation requires more energy and resources. In many cases temperature monitoring is required to guarantee the quality of the product. Commodities like meats [1] can spoil if temperatures rise, vaccines require even stricter temperature regimes as they can lose efficiency when exposed to higher or lower temperatures than recommended [2]. In both cases temperature fluctuations out of the required range require recall of the product. This can be very expensive and sometimes life threatening [3] in case of vaccines and first aid kits.

Temperature sensitive product logistics require cold chain - continuous low temperature regime from storage after production to transport and final storage before getting to the end consumer. Usually, logistics managers are responsible that the cold chain is not broken at any point, ensuring the required temperature regime. Additionally, there are costs, $\mathrm{CO}_{2}$ footprint and other factors that need to be considered when cold chain logistics is being developed. There are multiple aspects logistics management need to consider - required temperature regime, available infrastructure, time frame and available financial resources [4]. In every case risk assessment needs to be conducted and precautions weighed. Multiple tools can help

* Corresponding author.

E-mail address: Ilze.Vamza@rtu.lv 
to ensure efficient product transportation - the Global Positioning System [5] along with temperature logging [3] can provide real-time information on the location and temperature of the product. Temperature logging can provide information, but in no way, is it a tool that can impact the situation, it only helps to elucidate the weak points in the cold chain. Temperature fluctuations of transported goods can be prevented by using dry ice or cold packs [3] and thermal insulation packaging [6].

All the above mentioned equipment and tools impact the carbon footprint of the whole cold chain. The most popular thermal insulation material used in temperature sensitive product transportation is polystyrene [41] - styrene is synthesized from ethylene and benzene and then polymerized [7], [8]. Ethylene and benzene are chemicals acquired in petroleum refining process [9] making polystyrene a non-renewable polymer. In addition, its carbon footprint is considerable making up $64.98 \mathrm{~kg}$ of $\mathrm{CO}_{2 \mathrm{eq}}$ per $\mathrm{m}^{3}$ expanded polystyrene with thermal conductivity of $0.031 \mathrm{~W} / \mathrm{m} / \mathrm{K}$ [10]. Polystyrene has a negative impact on the environment not only in production process, but at the end of its use as well. Song et al. experiment results show that polystyrene can lose its mass for as much as $5 \%$ after a month of exposure to the sun and outdoor weather, nevertheless polystyrene's mineralization can take hundreds or even thousands of years [11]. This polymer breaks down when exposed to UV light, natural exposure from the sun is sufficient for polystyrene to break down in microplastics and even nanoplastics [11]. In this form it is dispersed in natural bodies of water where it is ingested by marine life and ends up in the food chain leading to humans [12].

To address the environmental issues regarding cold chain and logistics overall, green logistics approach has been implemented. Green logistics deals with reduction of the negative aspects of goods transportation - like noise, air pollution, greenhouse gas emissions, accidents resulting in wastage and so on [13]. In many companies the necessity for temperature sensitive product transportation is so rare that it is outsourced, leaving the decision making regarding packaging, vehicles and the rest of logistics in the hands of another company [14]. According to Lammgard and Andersson (2014), around $70 \%$ of companies claim that the environmental aspect is important when outsourcing the transportation service for their goods [15].

The World Health Organization (WHO) has recognized the impact of global vaccine cold chains on the environment. Inefficient fuel use, poor quality insulation of buildings, fossil fuel use and many more factors contribute to a negative environmental impact [16]. Packaging has been recognized as another important contributor to the negative impact on the environment, hence the WHO is in search of more sustainable packaging regarding vaccine logistics, including thermal packaging used for temperature sensitive product shipment [17].

Already 10 years ago corn-based packaging was highlighted by the WHO as a sustainable choice in vaccine transportation [17]. Today there are companies like 'Greencellfoam' [18] that offer biodegradable solutions made from corn, this material is often provided by logistics companies under a generic name - starch-based packing peanuts. The technology behind starch-based packing peanuts is similar to polystyrene extrusion. Usually, some kind of blowing agent (air or supercritical $\mathrm{CO}_{2}$ ) is used to enable air bubble production in the extruded material [19], [20]. Although this material is completely compostable with lower negative impact at the end of its life in comparison to conventional plastic foams, it is denser [19], hence more expensive to use in air cargo shipping. In addition, the hydrophilic properties of starch-based foams make them prone to size reduction in humid environments and even dissolving if the material comes in contact with water. To counteract the hydrophilic nature, there are attempts to merge starch with small amounts of plastics, as this reduces the carbon footprint in comparison to conventional plastic foams while increasing the product water resistance [21]. 
Another commercially available thermal insulation material for packaging use is mycelium based. 'Ecovative' were the first pioneers leading this material to the market in 2007. Agricultural and wood waste can be used to produce mycelium-based insulation material [22]. As seen in nature, fungus weaves through the substrate and interlocks the substrate particles in a rigid structure. This can happen due to fungus morphology - its cells are making filamentous structures called hyphae - these strand-like structures allow for fungus to connect with each other and create a network [23]. Substrate locking with hyphae can result in stiff material with better strength than polystyrene. In addition to mycelium-based materials produced from agricultural and wood waste being biodegradable, production technology consumes considerably less energy than polystyrene production - $652 \mathrm{MJ}$ and $4667 \mathrm{MJ}$, respectively [22]. The downside of mycelium insulation materials is production time as it is limited to the slow growth of mycelium [24].

Another thermal insulation material produced from waste is feather insulation found on the market under the brand name of 'Pluumo' [25]. In the European Union alone around 3 million tonnes of feather waste are created from poultry farms annually. Feathers contain natural fibers that can be used in non-woven form to achieve low thermal conductivity of 0.030 $\mathrm{W} / \mathrm{m} \cdot \mathrm{K}$ providing better thermal insulation than polystyrene foam. Feather insulation has the same weakness as other thermal insulation materials already discussed - water. The fibre structure makes it easy for water to seep into the material with capillary forces [26]. Hence waterbirds constantly preen their feathers with a waxy secretion to make them water resistant [27]. Plucked and processed feathers lose their coating making them prone to water absorption. The weak spot of thermal packaging from feather mat is the base of the box where all the weight of transported goods is pushing down - reduced thickness of feather mat greatly impacts the quality of packaging by increasing the thermal conductivity [26]. A similar material prone to the same problem is made out of sheep wool - on the market under the name 'Woolcool' [28]. Although the macroscopic structure of wool is different from feathers, it is made of the same protein fibers called keratin, making the material hydrophilic. Like the bird uropygial gland, sheep have glands on the skin that produce waxy substance called lanolin, impregnating the wool to make it water repellent. Sheep wool has good thermal insulation properties of $0.033 \mathrm{~W} / \mathrm{m} / \mathrm{K}$ [29].

As shown above, there are multiple new and innovative thermal packaging solutions on the market, but none have been as successful as polystyrene boxes. There are many criteria that logistics management need to consider while choosing the right packaging. Some of the more environmentally sustainable packaging solutions provide more efficient thermal insulation than others but all fall short in some respects, hence it is necessary to elucidate the most important criteria evaluated from the industry's perspective that is dealing with temperature sensitive product transportation. In this paper we are using pairwise comparison to determine the most important factors regarding thermal packaging from the perspective of logistics managers in Latvia's biotechnology, pharmacology, and fine chemical enterprises.

\section{MethodS}

\subsection{Criteria identification}

Initial criteria for thermal packaging comparison were identified in open interviews with representatives of companies working in the pharmaceutical and fine chemicals and logistics field. By allowing representatives to answer to open questions like 'How is thermal packaging chosen?', criteria and their indicators were elucidated. In many cases it became clear that industry is not using numerical indicators for each criterion. For example, criterion 
'sustainable' was often described as non-fossil raw material without any numerical value assigned to the corresponding criterion. Further, literature and product data sheets were analysed to validate the criteria. The analysed product data sheets contained information based on performance, for example, hours held in temperature below $+8{ }^{\circ} \mathrm{C}$ [25], [28], [30], indicators like thermal conductivity and density were found in scientific literature on corresponding materials [19], [22], [26].

\subsection{Weighing}

To determine the importance of 12 criteria, pairwise comparison was conducted. As it is impossible for humans to grasp the reciprocal relationships of 12 criteria at the same time, the method for pair analysis was chosen. Using this approach, experts were asked to compare only two criteria at a time, each expert did a total of 66 comparisons. Comparison was done verbally as suggested by Saaty et al. 2010 [31] by determining, is one criteria equally important as the other, less important or more important. After verbal comparison, numerical values were assigned to each compared pair using a scale of 1 to 9 . In the chosen scale 9 was signifying very high importance, 6 - strong to very strong importance, 3 - moderate importance and 1 - equal importance [32].

\section{TABLE 1. THERMAL PACKAGING CRITERIA USED FOR PAIRWISE COMPARISON}

\begin{tabular}{|c|c|}
\hline Criteria & Description \\
\hline Odour & Material has no considerable scent \\
\hline $\begin{array}{l}\text { Resistance to } \\
\text { humidity }\end{array}$ & Material does not dissolve or get damaged to the point it loses its thermal resistance \\
\hline $\begin{array}{l}\text { Vapour } \\
\text { resistance, } \mathrm{m}\end{array}$ & $\begin{array}{l}S_{\mathrm{d}} \text { value of thermal insulation material. Represents the resistance to water vapour taking up certain } \\
\text { air layer thickness }[\mathrm{m}] . \text { Mostly relevant for shipments with dry ice }\end{array}$ \\
\hline $\begin{array}{l}\text { Branding } \\
\text { opportunities }\end{array}$ & Material can be printed on \\
\hline Sustainability & Raw material of thermal packaging is renewable \\
\hline $\begin{array}{l}\text { Ability to hold } \\
\text { temperature, } \\
\text { hours }\end{array}$ & $\begin{array}{l}\text { Packaging can hold specific temperature for more than } 24 \text { hours. Criterion represents in situ } \\
\text { measurements of temperature in relevant environment and packed test goods - representing goods } \\
\text { that would be transported. }\end{array}$ \\
\hline $\begin{array}{l}\text { Thermal } \\
\text { conductivity, } \\
\mathrm{W} / \mathrm{m} / \mathrm{K}\end{array}$ & $\begin{array}{l}\text { In line with this study, } 0.04 \mathrm{~W} / \mathrm{m} / \mathrm{K} \text { was considered the threshold for thermal conductivity to be } \\
\text { considered low. Thermal conductivity characterizes the material by its ability to conduct heat } \\
\text { energy. Heat energy is always transferred down the gradient. }\end{array}$ \\
\hline Reusability & Material can be re-used multiple times \\
\hline $\begin{array}{l}\text { Available in } \\
\text { multiple sizes }\end{array}$ & Multiple dimension options are available \\
\hline $\begin{array}{l}\text { Price, EUR per } \\
391 \text { box }\end{array}$ & Per packaging solution \\
\hline Durability & Material can be used without supportive tertiary packaging (e.g., cardboard box) \\
\hline Density, $\mathrm{kg} / \mathrm{m}^{3}$ & Weight to volume ratio of packaging solution \\
\hline
\end{tabular}

Overall, 10 questionnaires were disseminated among the identified pharmaceutical and fine chemical industry enterprises in Latvia, including big companies like Grindex and Olainfarm. It was expected that the approached companies were heavily impacted by the global pandemic, only five responded and three were eligible to questions as companies made their own decisions regarding temperature sensitive product logistics. Two companies outsourced 
this service hence were unsuitable for multi criteria analysis and criteria comparison, nevertheless their reported practice will be discussed in the Results part of this study. The chosen companies assigned the questionnaire to logistics team experts within the company. All the criteria experts comparisons are compiled in Table 1.

Mathematically all the chosen criteria are plotted on a matrix and by solving them, eigenvalues can be found. These values, also called eigenvectors, represent the importance of each criteria - a higher value means higher importance in the final decision. Indicative eigenvalues were calculated in Microsoft Excel [33] and used for further analysis. A consistency threshold of 0.2 was used, as done before [34] when multiple stakeholders were surveyed.

\subsection{Multi criteria analysis}

To compare thermal packaging materials, Technique for Order of Preference by Similarity to Ideal Solution (TOPSIS) was used. TOPSIS allows to compare multiple options by multiple criteria. The first stage of TOPSIS was gathering data set of indicators for each thermal packaging material. Data were acquired from product data sheets [25], [28], [30] and patent claims. In the second step, normalization of indicators was performed. Values were weighed based on responses from experts as described in section 2.2. In the next step normalized values were weighed, directions of vectors and their proximity to desirable and avoidable results were calculated. The final step was to calculate the proximity to the ideal solution represented by a value of 1 [35].

TOPSIS methodology was chosen because it requires only a few indicators, while providing comparable data to draw conclusions. For further multi-criteria analysis, only criteria with comparable numerical values were chosen, reducing the number of criteria from 12 to 5 . Chosen criteria were density, thermal conductivity, environmental sustainability, ability to hold temperature, and price. Criteria like odour, availability in multiple dimensions were determined as on-off type of criteria - if material would have considerable odour, it would not be used, the same with availability in multiple dimensions - most of the companies needed the thermal packaging to be available in at least 3 different sizes. Cases where the thermal packaging producer does not offer multiple sizes, the product was not considered further. Resistance to humidity and vapour resistance are both important for certain kinds of transportation - transportation where there is a high humidity risk e.g. transportation with ice, and transportation using dry ice accordingly. Reusability and durability were excluded as expert principles for determining material's accordance for reuse differed. Durability as material's ability to be used without supporting cardboard box was excluded from further analysis as this option was rarely used by experts in their represented companies.

The basic assumption of TOPSIS methodology is that the most preferred solution is one with the shortest distance to the desirable result and greatest distance from the result to be avoided. Multiple innovative packaging materials along with conventional polystyrene were compared regarding five criteria.

\section{Results}

\subsection{Importance of criteria}

Weighing process using pairwise comparison of all 12 criteria gives an overall look on the importance of each criterion in relation to the rest. The results of weighing are shown in Fig. 1. 


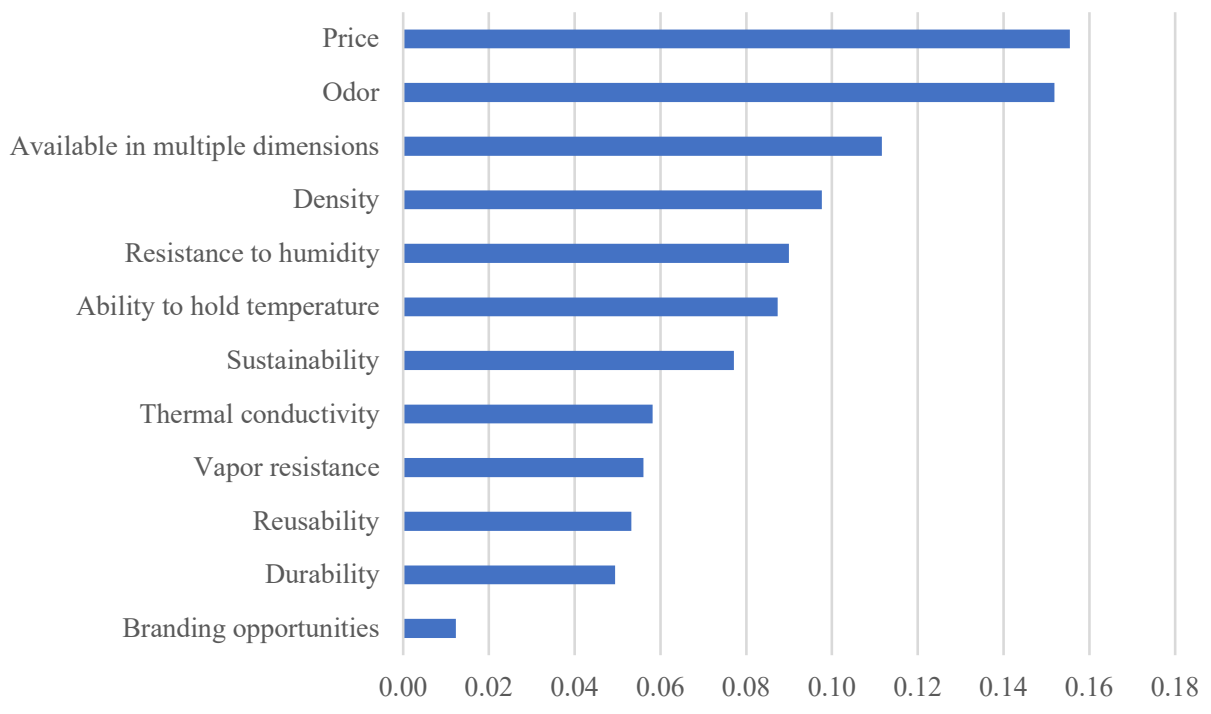

Fig. 1. Weighed criteria in ascending order regarding their importance.

Interestingly, enterprises with specialty in fine chemicals and companies using thermal packaging for internal use, like sample transfer among branches, expressed the importance of reusable packaging. In these cases, companies are preferring thermal packaging that can withstand at least 10 application times. On the contrary - pharmaceutical companies claimed that packaging was used only one time, as its visual appearance after one use is no longer suitable for medication.

To compare the thermal packaging options available on the market, only five criteria were chosen for further analysis. Criteria like neutral smell was excluded as none of the materials available on the market reported to have a scent and this would be only an on-off criteria. Availability of dimensions was not analysed as experts from different companies were interested in various sizes, making this criterion specific to each case.

Water resistance was considered as being an important criterion, but it covers a lot of aspects: (1) water absorption; (2) water release after absorption; (3) whether material stays intact after being exposed to water. The third aspect is very important, at the same time it should be considered for each specific case. For example, corn-starch foam could be the most preferred option for shipping electronics, as it can absorb mechanical shock and protect the goods, but as it dissolves in water, it cannot be used in shipments with higher humidity, e.g., iced products, as humidity would destroy the packaging. At the same time water resistance is not important in the case of electronics as usually the cargo is protected from such and in cases where the cargo is compromised by water, the shipment is recalled.

Additionally, criteria for durability were excluded along with vapour resistance, repeated use, and graphical identity. Vapour resistance was excluded as it is most important for shipments with dry ice and companies are avoiding this shipping option due to the hazardous nature of dry ice. Each company considered various re-use times as optimal - experts from testing laboratories and other companies who use the packaging only internally admitted that they reuse the packaging at least ten times and it can look quite scuffed but its functionality is the most important. On the contrary, pharmaceutical companies used the packaging only one time as its visual appearance was compromised after use. Graphical identity was the least 
important criterion and similarly as scent - it is an on-off criterion, so it was left out of further analysis. Criteria chosen for further analysis were weighed and results are depicted in Fig. 2.

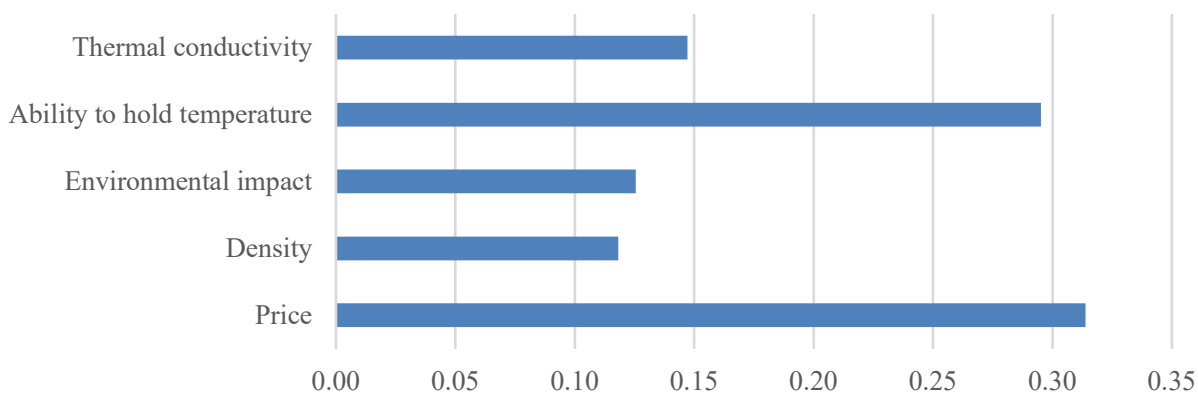

Fig. 2. Chosen quantitative criteria and their weights showing the importance of each criterion in the final decision making.

As shown above, after narrowing down to five criteria, price, and ability to hold temperature took a considerable lead as being the two most important criteria, they together accounted for more than a half of the impact on the final decision.

\subsection{Most preferable material}

To evaluate the most preferable 'green' thermal packaging available on the market, four products were compared to polystyrene packaging. Using previously determined weights, the following thermal insulation materials were compared: non-woven feathers, non-woven wool, starch foam, mycelium, and polystyrene (Fig. 3).

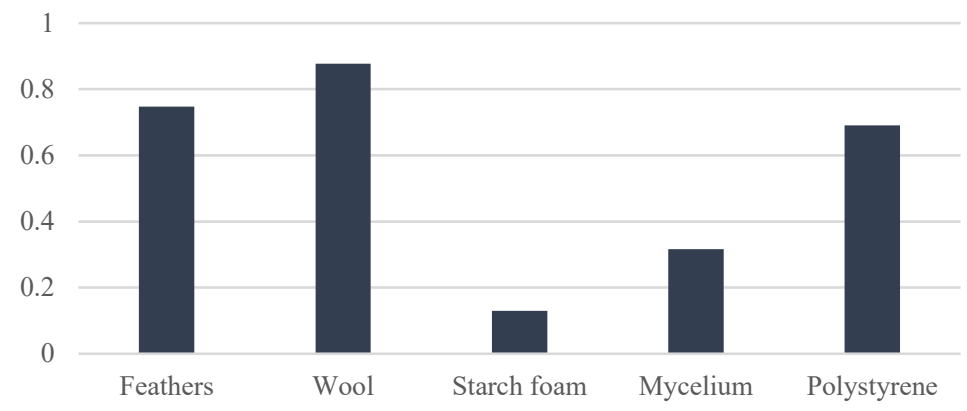

Fig. 3. Technique for Order of Preference by Similarity to Ideal Solution ranking of thermal packaging materials. Y axis represents the proximity to ideal solution 1.

Among the thermal packaging options, the closest proximity to ideal solution (represented by 1 on $\mathrm{Y}$ axis in Fig. 3) by applying TOPSIS method was assigned to non-woven wool followed by feathers and polystyrene, the lowest rank was assigned to starch foam and mycelium was second-to-last in the ranking.

\section{DiscuSSION}

The findings of the study show that price is the most important factor when choosing 
thermal packaging for temperature sensitive pharmacology and fine chemical applications. Nevertheless, performance of holding temperature in a specific range was the second most important criterion in the reduced criteria set. Among obvious factors like density and availability in multiple sizes, the scent of the material was elucidated as a factor of considerable importance. Experts explained that material cannot have any strong odours to be used as thermal packaging. Concern that scent might linger and compromise the neutral scent of product itself was expressed.

Due to the high number of criteria analysed, a consistency ratio of 0.2 was chosen [34], although according to Saaty [31] 0.1 is considered as the optimal threshold. Saaty's approach is based on crisp values - criteria can be ranked in linear order. Authors like Ju [36], Ishizaka and Nguyen [35], and recently Lin [37] have argued that humans cannot comprehend complex relationships between many criteria and fuzzy numbers should be used for more representative comparison. Fuzzy values are characterized by coordinates representing area, opposite to crisp values representing vectors with one direction.

Inconsistencies in this research mainly arose from the unrealistic evaluation of the importance of the sustainability criterion - when other criteria were compared to the sustainability criterion, higher importance was assigned to sustainability, however, when sustainability was compared to other criteria its importance was scored lower, hence the inconsistency.

Analytical hierarchy process was conducted according to Satty's principles with crisp values, as fuzzy values have not yet gained consensus amongst the mathematics community [38]. Nevertheless, inconsistency level and data analysis showed experts struggle to prioritize sustainability versus price and other criteria, criteria used for choosing thermal packaging at this point might not have a consistent hierarchy at all. Environmental aspects are important as shown by survey that showed - around $70 \%$ of enterprises claim that environmental aspects often signified by environmental certification is an important factor when considering transportation services [15], however the results show a different situation. In a single case, one logistics company expert explained that a company can boost its environmental performance by reducing the administration's impact on the environment, like - reduce the printed paper amount and implement other office-oriented policies. The example shows that environmental certificates do not always manifest the transportation part of the business and, although sustainability is important, at this point it is hard to determine the hierarchy of sustainability and price and other criteria.

Another finding in this study confirms that industry values higher the actual in situ performance over laboratory tested attributes. Actual performance measured by hours the material could hold the temperature in a specific range was twice as important as thermal conductivity. Final performance or ability to hold temperature is dependent on thermal conductivity, specific heat capacity and thickness of the insulation layer. As discussed above, even deformation of the thermal insulation layer can impact the ability to hold temperature, soft materials like wool and feather get compressed under the weight and their thermal conductivity increases, seeing their performance in a real life situation can help to evaluate overall performance. As discussed before, time is crucial for the quality of many products, e.g., meats and vaccines [1], [2]. Overall performance of the thermal packaging is impacted by thermal conductivity [22], heat capacity [39] and, in some cases, vapour resistance [22]. Performance tests in $+30{ }^{\circ} \mathrm{C}$ temperature surroundings are preferred, final packaging performance is impacted not only by thermal insulation layer properties, but the product and the chosen cooling agent as well. So-called gel packs are ubiquitous cooling agents, hence performance testing is conducted by using gel packs for maintaining temperature levels[6]. Thermal packaging-producing companies have discovered the importance of time and depict 
multiple temperature regime tests in their datasheets [28]. The World Health Organization has developed an independent type-testing protocol for thermal packaging in various conditions for various cold and hot ambient temperatures [40]. For thermal packaging producers these guidelines only serve as advice for the testing setup - weight and dimensions for tested thermal insulation packaging were not specified in any of the analysed data sheets. Avoiding factoring in weight might lead to completely different results while in use, as mentioned before, deformation of packaging can lead to compromised thermal resistance.

Despite polystyrene's popularity, our research shows that thermal packaging made from expanded polystyrene is not the most preferable choice when compared to some environmentally sustainable thermal packaging options. Two products - 'Woolcool' and 'Pluumo' outperformed polystyrene packaging when compared in price, density, ability to hold temperature, environmental impact, and thermal conductivity. Our research elucidates the discrepancy between theoretically preferable and actual choices made by logistics managers. Results signal that environmentally preferable solutions have caught up conventional packaging and it is worthwhile for logistics managers to consider switching to new thermal packaging solutions. Multi criteria analysis using crisp numbers could be used by logistics managers to decide on the most preferrable thermal packaging option. Although this paper provides general results regarding most preferable thermal packaging, each company can tailor the weights of criteria to align them with company values. Consequently, research teams developing sustainable alternatives to conventional thermal packaging materials could use the weights calculated in this study to gain perspective on respective material's performance regarding industry needs. Although sustainability criterion is important, according to calculated weights - price and ability to hold temperature prevails. Although ability to hold temperature will not lose its importance, the price criterion will continue to be impacted by green initiatives and the national natural resource tax.

\section{REFERENCES}

[1] Singh S., Gaikwad K. K., Lee M., Lee Y. S. Temperature sensitive smart packaging for monitoring the shelf life of fresh beef. J. Food Eng. 2018:234:41-49. https://doi.org/10.1016/j.jfoodeng.2018.04.014

[2] Hanson C. M., George A. M., Sawadogo A., Schreiber B. Is freezing in the vaccine cold chain an ongoing issue? A literature review. Vaccine 2017:35(17):2127-2133. https://doi.org/10.1016/j.vaccine.2016.09.070

[3] Kartoglu U., Milstien J. Tools and approaches to ensure quality of vaccines throughout the cold chain. Expert Rev. Vaccines 2014:13(7):843-854. https://doi.org/10.1586/14760584.2014.923761

[4] Mariano E. B., Gobbo J. A., Camioto F. de C., do N. Rebelatto D. A. $\mathrm{CO}_{2}$ emissions and logistics performance: a composite index proposal. Journal of Cleaner Production 2017:163:166-178.

https://doi.org/10.1016/j.jclepro.2016.05.084

[5] Pan C., Yu S., Li S. Research on the development mode and evaluation system of green cold chain logistics in China. Chinese Control Conf. CCC. 2017. https://doi.org/10.23919/ChiCC.2017.8028547

[6] Wang K., Yang L., Kucharek M. Investigation of the effect of thermal insulation materials on packaging performance. Packaging Technology and Science 2020:33(6):227-236. https://doi.org/10.1002/pts.2500

[7] Vaughan B. A., Webster-Gardiner M. S., Cundari T. R., Gunnoe T. B. A rhodium catalyst for single-step styrene production from benzene and ethylene. Science 2015:348(6233):421-424. https://doi.org/10.1126/science.aaa2260

[8] Pei D., Mo Z.-H., Xu R. W., Zhang S., Wu Y. X. Cross-Linked Quaternized Poly(styrene-b-(ethylene-co-butylene)b-styrene) for Anion Exchange Membrane: Synthesis, Characterization and Properties. ACS Appl. Mater. Interfaces 2016:8(31):20329-20341. https://doi.org/10.1021/acsami.6b04590

[9] Wei W., Lv Z., Yang G., Cheng S., Li Y., Wang L. VOCs emission rate estimate for complicated industrial area source using an inverse-dispersion calculation method: A case study on a petroleum refinery in Northern China, Environ. Pollut. 2016:218:681-688. https://doi.org/10.1016/j.envpol.2016.07.062

[10] Lewis E. Environmental Product Declaration. In Lewis E. et al. (eds) Sustainaspeak. Routledge, 2018:106-107. https://doi.org/10.4324/9781315270326-75

[11] Song Y. K., Hong S. H., Eo S., Han G. M., Shim W. J. Rapid Production of Micro- And Nanoplastics by Fragmentation of Expanded Polystyrene Exposed to Sunlight. Environ. Sci. Technol. 2020:54(18):11191-11200. https://doi.org/10.1021/acs.est.0c02288 
[12] Jovanović B. Ingestion of microplastics by fish and its potential consequences from a physical perspective. Integr. Environ. Assess. Manag. 2017:13(3):510-515. https://doi.org/10.1002/ieam.1913

[13] Dekker R., Bloemhof J., Mallidis I. Operations Research for green logistics - An overview of aspects, issues, contributions and challenges. Eur. J. Oper. Res. 2012:219(3):671-679. https://doi.org/10.1016/j.ejor.2011.11.010

[14] Rogerson S. Influence of freight transport purchasing processes on logistical variables related to $\mathrm{CO}_{2}$ emissions: a case study in Sweden. Int. J. Logist. Res. Appl. 2017:20(6):604-623. https://doi.org/10.1080/13675567.2017.1308472

[15] Lammgård C., Andersson D. Environmental considerations and trade-offs in purchasing of transportation services. Res. Transp. Bus. Manag 2014:10:45-52. https://doi.org/10.1016/j.rtbm.2014.04.003

[16] Need T. H. E. et al. Green supply chains: a glimpse into the future? [Online]. [Accessed: 16.04.2021]. Available: https://path.azureedge.net/media/documents/TS_opt_green_supply_chains.pdf

[17] Newland S. Sustainability in Vaccine Packaging Draft. $201 \overline{1}$.

[18] Greencellfoam, Greencellfoam. 2021. [Online]. [Accessed: 15.04.2021]. Available: https://greencellfoam.com/

[19] Mariam I., Cho K. Y., Rizvi S. S. H. Thermal properties of starch-based biodegradable foams produced using Supercritical Fluid Extrusion (SCFX). Int. J. Food Prop. 2008:11(2):415-426. https://doi.org/10.1080/10942910701444705

[20] Kalambur S. B., Rizvi S. S. Starch-based nanocomposites by reactive extrusion processing. Polym. Int. 2004:53(10):1413-1416. https://doi.org/10.1002/pi.1478

[21] Kalambur S., Rizvi S. S. H. An overview of starch-based plastic blends from reactive extrusion. J. Plast. Film Sheeting 2006:22(1):39-58. https://doi.org/10.1177/8756087906062729

[22] Bruin S. Mycelium: a Building Block for Parkstad Limburg. 2018.

[23] Schmieder S. S. et al. Bidirectional Propagation of Signals and Nutrients in Fungal Networks via Specialized Hyphae, Curr. Biol. 2019:29(2):217-228. https://doi.org/10.1016/j.cub.2018.11.058

[24] Boswell G. P., Jacobs H., Davidson F. A., Gadd G. M., Ritz K. Growth and function of fungal mycelia in heterogeneous environments. Bull. Math. Biol. 2003:65(3):447-477. https://doi.org/10.1016/S0092-8240(03)00003-X

[25] Home - pluumo. [Online]. [Accessed: 29.03.2021]. Available: https://www.pluumo.com/home

[26] Dieckmann E., Nagy B., Yiakoumetti K., Sheldrick L., Cheeseman C. Thermal insulation packaging for cold-chain deliveries made from feathers, Food Packag. Shelf Life 2019:21:1003609. https://doi.org/10.1016/j.fpsl.2019.100360

[27] Braun M. S., Sporer F., Zimmermann S., Wink M. Birds, feather-degrading bacteria and preen glands: The antimicrobial activity of preen gland secretions from turkeys (Meleagris gallopavo) is amplified by keratinase. FEMS Microbiol. Ecol. 2018:94(9):1-14. https://doi.org/10.1093/femsec/fiy117

[28] Woolcool Thermal Insulated Packaging Company. Food \& Pharmaceutical. [Online]. [Accessed: 29.03.2021]. Available: https://www.woolcool.com/

[29] Tuzcu T. M. Hygro-Thermal Properties of Sheep Wool Insulation. 2007.

[30] High Performing Foam Packaging - Green Cell Foam. [Online]. [Accessed: 15.04.2021]. Available: https://greencellfoam.com/data

[31] Saaty T. L., Sodenkamp M. The Analytic Hierarchy and Analytic Network Measurement Processes: The Measurement of Intangibles. In Zopounidis C., Pardalos P. (eds) Handbook of Multicriteria Analysis. Applied Optimization, vol. 103. Springer, Berlin, Heidelberg, 2010. https://doi.org/10.1007/978-3-540-92828-7 4

[32] Saaty T. L. Deriving the ahp 1-9 scale from first principles. Proc. - $6^{\text {th }}$ ISA $\bar{A} P$, 2001. https://doi.org/10.13033/isahp.y2001.030

[33] Goepel K. D. Implementing the Analytic Hierarchy Process as a Standard Method for Multi-Criteria Decision Making in Corporate Enterprises - a New AHP Excel Template with Multiple Inputs. Proceedings of the International Symposium on the Analytic Hierarchy Process, 2013. https://doi.org/10.13033/isahp.y2013.047

[34] Adem Esmail B., Geneletti D. Multi-criteria decision analysis for nature conservation: A review of 20 years of applications. Methods Ecol. Evol. 2018:9(1):42-53. https://doi.org/10.1111/2041-210X.12899

[35] Ishizaka A., Nguyen N. H. Calibrated fuzzy AHP for current bank account selection. Expert Syst. Appl. 2013:40:(9):3775-3783. https://doi.org/10.1016/j.eswa.2012.12.089

[36] Ju Y., Wang A., Liu X. Evaluating emergency response capacity by fuzzy AHP and 2-tuple fuzzy linguistic approach. Expert Syst. Appl. 2012:39(8):6972-6981. https://doi.org/10.1016/i.eswa.2012.01.061

[37] Lin C. N. A fuzzy analytic hierarchy process-based analysis of the dynamic sustainable management index in leisure agriculture. Sustain. 2020:12(13)5395. https://doi.org/10.3390/su12135395

[38] Kubler S., Derigent W., Voisin A., Robert J., Le Traon Y., Viedma E. H. Measuring inconsistency and deriving priorities from fuzzy pairwise comparison matrices using the knowledge-based consistency index. Knowledge-Based Syst. 2018:162:147-160. https://doi.org/10.1016/j.knosys.2018.09.015

[39] Singh S., Gaikwad K. K., Lee Y. S. Phase change materials for advanced cooling packaging. Environ. Chem. Lett. 2018:16(3):845-859. https://doi.org/10.1007/s10311-018-0726-7

[40] PQS Independent type-testing protocol. 2010.

[41] Insulated Packaging Market - Growth, Trends, Forecasts (2020-2025). [Online]. [Accessed: 16.04.2021]. Available: https://www.globenewswire.com/news-release/2020/12/16/2146158/0/en/Insulated-Packaging-Market-GrowthTrends-Forecasts-2020-2025.html 